\title{
Trabalho docente na educação superior brasileira: mercantilização das relações e heteronomia acadêmica ${ }^{1}$
}

\author{
Deise Mancebo \\ Universidade do Estado do Rio de Janeiro, Brasil
}

\begin{abstract}
Resumo
O artigo discute a flexibilização das relações contratuais do trabalho docente de instituições de educação superior; as transformações ocorridas na sua produção (ensino, pesquisa e extensão) e as mudanças experimentadas na cultura das instituições de educação superior no Brasil. Para tal, foram consultados os principais dispositivos legais e diversos indicadores oficiais, tomando como eixo básico da análise, a mercantilização da educação superior, no marco das mudanças acontecidas no mundo do trabalho, a partir dos anos 1970 em escala mundial.
\end{abstract}

Palavras-chave

Trabalho Docente; Educação Superior; Privatização da Educação Superior

\section{Introdução}

A literatura crítica que problematiza o trabalho docente de educação superior tem aumentado nos últimos anos, no Brasil, em decorrência de uma percepção generalizada de professores universitários e dos pesquisadores dessa área quanto ao aumento, intensificação e desvalorização do seu trabalho.

Tais estudos remetem-se à dimensão da flexibilização das relações contratuais de trabalho; às transformações ocorridas na produção docente 
(ensino, pesquisa e extensão) e/ou às transformações experimentadas na cultura das instituições de educação superior e do trabalho docente.

Pretende-se neste artigo seguir este mesmo caminho contemplando, na medida do possível, o sistema de educação superior brasileiro como um todo, cotejando dados relacionados às instituições dos setores público e privado (composto por instituições comunitárias, confessionais e particulares), bem como a graduação e a pós-graduação².

O eixo básico da análise é a mercantilização da educação superior, no marco das mudanças acontecidas no mundo do trabalho, a partir dos anos 70 em escala mundial. Entende-se, portanto, que as transformações observáveis na situação, atividades e cultura docentes precisam ser situadas, como demais ramos do trabalho, na crise de acumulação do capital ocorrida em âmbito internacional, por volta do início da década de 1970, mesmo que as mudanças implementadas na educação superior só tenham ganho visibilidade no Brasil a partir dos 90 .

Sobre esse período, diversos estudos identificaram uma queda significativa nos ritmos do crescimento das economias capitalistas, que passaram a registrar declínio e estagnação. A tendência decrescente da taxa de lucro, no campo da discussão marxista, tem sido explicada em relação ao próprio processo de acumulação de capital que, levando ao limite os níveis de produtividade e de competição, faz explodir crises cuja superação requer, dentre outras medidas, o aumento da taxa de exploração sobre o trabalho (Marx, 1981).

Assim, no contexto histórico demarcado a partir da crise da década de 1970, o capital iniciou a construção de novas configurações que combinaram diversos fatores numa escala que envolveu desde o barateamento da mãode-obra por meio da reestruturação dos processos de trabalho, a flexibilização do trabalho e da produção de mercadorias (Antunes, 1999; Alves, 2000), até a monumental desregulamentação, de que as aberturas para o mercado externo, as políticas de ajuste fiscal e as privatizações, incluindo as dos serviços públicos, transferidos para a esfera da iniciativa privada foram as expressões mais visíveis ${ }^{3}$.

No Brasil, a educação superior não escapou dessa reordenação mais geral, de modo que os sistemas educacionais foram submetidos a profundos 
processos de privatização, com a expansão da educação superior pela via privada, e a introdução, nas instituições públicas, de uma tendência - cada vez mais predominante - de mercantilização do trabalho docente, tornando a gestão das universidades cada vez mais parecida com a de uma empresa, esvaecendo o seu caráter de instituição da sociedade voltada para a formação humana e para a produção do conhecimento engajado na solução de problemas nacionais (Leher \& Lopes, 2008).

\section{Privatização do sistema de educação superior no Brasil}

Efetivamente, o sistema de educação superior brasileiro vem se expandindo no sentido da iniciativa privada 4 e afirmar a expansão da educação superior nesta direção significa dizer que os produtos oferecidos dão-se, em sua maioria, num cenário em que predominam as atividades relacionadas ao ensino de graduação (sem atividades de pesquisa e extensão) e onde o financiamento ocorre com a participação ativa do consumidor de serviços educacionais, numa clara definição da educação superior como mercadoria.

$\mathrm{Na}$ realidade, se tomarmos a análise da educação superior brasileira historicamente, verifica-se que a privatização do sistema não é um fenômeno novo, nem exclusivo aos últimos governos e que, mesmo considerando a permanente tensão entre interesses públicos e privados no âmbito do próprio Estado e das demais esferas da atividade humana, mesmo que se relevem as inúmeras lutas travadas em prol do pólo público, pode-se identificar uma crescente privatização do sistema de educação superior no país, pelo menos desde a Lei no 5540 de 1968 ou Lei da Reforma Universitária de 68, elaborada e posta em vigor durante a ditadura militar (Mancebo; Silva Júnior \& Oliveira, 2008: 8).

Todavia, é a partir da década de 1990, que se inicia, no Brasil, um consistente processo de redução de gastos públicos federais para o conjunto das instituições federais de ensino superior (IFES) e se desencadeia a retomada, em grau muito mais aprofundado que na década de 1970, sob a ditadura militar, da privatização desse nível de ensino. Assim, muito embora a privatização da educação superior não se restrinja aos dois últimos governos (o de Fernando Henrique Cardoso de 1995 a 2002 e o de Lula da Silva, a 
partir de 2003), foi neste período que ganhou um curso extraordinário, já que ambos aplicaram a máxima neoliberal, segundo a qual deve haver deserção do Estado de seu necessário protagonismo na implementação da universidade como um bem público e direito de cidadania (Mancebo; Silva Júnior; Oliveira, 2008: 8).

Assim, se observarmos, por exemplo, a relação de matrículas em cursos presenciais oferecidas por instituições privadas e públicas, conforme dados oficiais (MEC.INEP, 2002; 2006a; 2008), verifica-se que ocorreu um aumento em favor das primeiras. Em 1995, início do primeiro mandato do presidente Fernando Henrique Cardoso, podia-se registrar a oferta de $39 \%$ das matrículas em instituições públicas e de $61 \%$ nas privadas. Em 2002, no final do seu segundo mandato, a tendência à privatização do sistema se intensifica com o oferecimento de $69,7 \%$ de matrículas nas instituições privadas. A base para a compreensão desse comportamento das matrículas no ensino superior brasileiro reside num conjunto de ações políticoadministrativas, ocorridas no octênio do governo de Fernando Henrique Cardoso, tanto pela via legislativa, quanto por medidas governamentais ostensivas de restrição do crescimento do setor público federal e de incentivo à expansão do setor privado.

No governo Lula da Silva (a partir de 2003), a despeito da expectativa alimentada por muitos no sentido da reversão deste quadro de empresariamento da educação superior, a dinâmica privatista permaneceu. No mesmo diapasão em que houve um compromisso desse governo quanto à continuidade dos padrões político-administrativos adotados pelo governo anterior em relação ao capital financeiro internacional - vistos como pressupostos da governabilidade e do fim da vulnerabilidade externa do país; na educação, também não se assistiu a nenhuma grande ruptura; antes, a quase continuidade das teses defendidas e postas em prática pelo governo anterior. Conforme Sguissardi (2006) analisa essa conjuntura:

O pano de fundo manteve-se basicamente o mesmo. Na área universitária, os instrumentos legais e as medidas administrativas, incluídas as financeiras, mostram que [... não ocorreram] rupturas com o processo anterior, a não ser, em certa medida, na adoção de novo sistema nacional de avaliação, com a recuperação dos montantes de recursos de custeio aos níveis de 1995 e com pequena expansão das IFES (p. 1039). 
Novamente, para a análise do quadro de privatização, o comportamento das matrículas nos cursos presenciais de graduação é um excelente indicador do que se está afirmando: em 2006, final do primeiro mandato de Lula da Silva, observa-se $26 \%$ matrículas nas IES públicas e $74,1 \%$ nas instituições privadas.

Dados do Censo da Educação Superior (MEC/INEP, 2006-b) registraram, ainda, um total de 2.270 instituições, sendo 2.022 privadas, sendo que, destas, 1.583 são particulares e assumidamente com fins lucrativos. Desse total, 7,8\% (178) são universidades e 92,2\% (2.092 instituições) são de outros formatos acadêmicos.

Bem verdade que esse cenário expansionista do setor privado, em que pese o respaldo dos dispositivos legais, vai apresentando sinais de esgotamento, mas não em função de um controle por parte do governo quanto à baixa qualidade de muitos desses cursos, devendo-se buscar as razões para a crise desse setor do capital nas condições concretas da população que não pode arcar com as mensalidades escolares. Na realidade, o próprio quadro de crise do setor privado tem resultado em novas formas de interpenetração entre as esferas pública e privada, por meio da ação do Estado no financiamento das instituições privadas, como é o caso da adoção de programas de apoio a instituições e alunos pobres como o Programa Universidade para Todos (PROUNI, 2005).

Se analisarmos a evolução das funções docentes das instituições de ensino superior (IES) públicas e privadas, a tendência à privatização do sistema de educação superior no Brasil torna-se ainda mais evidente. Se o crescimento da força de trabalho empregada nas IES públicas, registrado entre 1995 e 2005, foi de $19 \%$, nas IES privadas este foi de $270 \%$ ! A inversão dessa relação deu-se a partir de 1999 (segundo mandato de Fernando Henrique Cardoso) e, certamente, foi "preparada pela legislação que estimulou a multiplicação das instituições de ensino privadas e pela política de estagnação das IES públicas, explicitada fundamentalmente no arrocho orçamentário e no represamento de concursos" (Bosi, 2007: 158).

Se considerarmos as condições de trabalho nas instituições privadas, os dados apresentados permitem afirmar que a precarização do trabalho docente cresceu de modo extraordinário, no mesmo diapasão em que se perdeu em qualidade do ensino. Maria Cristina Nogueira Gramani (2008) 
escreveu recentemente um artigo onde constrói indicadores de "qualidade" para a orientação de instituições de ensino superior com capital aberto. Nele, a própria "consultora" adverte os acionistas:

[...] quando se trata uma instituição de ensino com valores comerciais ou princípios de mercado podem ocorrer situações como: contratação e demissão de colaboradores da instituição baseados em necessidades de mercado, recrutamento de estudantes com a finalidade de maior lucratividade, criação de programas rápidos a fim de maximizar o ganho, julgamento do desempenho de professores de acordo com a demanda dos consumidores, padronização dos currículos objetivando a eficiência econômica, entre outros (p.441).

Mas ocorrem no Brasil outros mecanismos de privatização além do crescimento numérico de instituições de ensino superior, como as parcerias entre as universidades públicas e as fundações de direito privado; a possibilidade de cobrança de cursos e venda de "serviços educacionais", dentre outros.

A transferência dos aportes patrimoniais, financeiros e humanos públicos das instituições públicas, para a iniciativa privada, por meio, principalmente, de alterações na superestrutura jurídica do Estado é outra tendência, que remete à privatização do sistema. Dois mecanismos merecem referência: o Programa Universidade para Todos (PROUNI, Lei no 11.096 de 13 de Janeiro de 2005), voltado para a iniciativa privada e a Lei de Inovação Tecnológica (Lei no 10.973 de 2 de Dezembro de 2004) que possibilita o trabalho de docentes das IES públicas nas empresas privadas.

Por fim, outra estratégia amplamente utilizada para a expansão do ensino de graduação pela matriz privatista tem ocorrido através da educação a distância, cuja oferta tem-se dado na esfera privada. Conforme Luiz Fernandes Dourado (2008), desde 1999 ocorre no Brasil

[...] um movimento de credenciamento de instituições de educação superior para a oferta de cursos na modalidade educação a distância (EaD). Tal dinâmica revela um movimento complementar ao processo expansionista dos cursos presenciais, mas articulado à sua lógica intrínseca, qual seja, 0 predomínio da oferta de matrículas pela esfera privada (Dourado, 2008: 105).

\section{Exploração e flexibilização do trabalho docente}

O aumento da exploração do trabalho docente, no Brasil, ademais como em todos os países latinos, deu-se em especial pela flexibilidade 
registrada nos regimes de trabalho e conseqüente quebra da carreira docente, onde ela existia. Do total de docentes cadastrados pelo censo do INEP (MEC/INEP, 2006b), apenas 16,9\% trabalham em regime de dedicação exclusiva e 18,6\% em tempo integral.

A Lei de Diretrizes e Bases da Educação Nacional (LDB - Lei no 9.394 de 20 de Dezembro de 1996) já havia estabelecido padrões bastante flexíveis para o trabalho docente, mas também impôs algumas restrições ao crescimento desordenado sistema. Assim, em seu Art. 52 afirma que as universidades, sendo "instituições pluridisciplinares de formação dos quadros profissionais de nível superior, de pesquisa, de extensão e de domínio e cultivo do saber humano", se caracterizam, dentre outros quesitos, por abrigarem um terço do corpo docente, pelo menos, com titulação acadêmica de mestrado ou doutorado (inciso II) e um terço do corpo docente em regime de tempo integral (inciso III). No Art. 88 das disposições transitórias, a mesma Lei fixa o prazo de oito anos para que esses dispositivos sejam cumpridos.

Desde dezembro de 2004, portanto, as universidades deveriam estar cumprindo o que determina a LDB. Todavia, pelos dados do Cadastro Nacional de Docentes (MEC/IEP, 2006-b), nota-se que, no item "regime de tempo integral", 75,6\% das instituições particulares não cumpriam a própria Lei. No sentido oposto a essa tendência, as públicas, com exceção de algumas instituições municipais e estaduais (mais precisamente, $8,3 \%$ do total), cumprem o dispositivo legal.

No caso das IES privadas, existem mais de 118 mil docentes em regime "horista", o que representa quase $50 \%$ de todos os docentes ocupados no ensino superior no Brasil, em 2005.

Para além do que pode ser quantificado e divulgado em indicadores oficiais, sabe-se da existência de outros expedientes menos ortodoxos de flexibilização da contratação e do regime de trabalho nas IES (tanto privadas, como públicas), como a utilização de alunos de pós-graduação como professores substitutos, bolsistas, monitores, professores-tutores para a educação a distância, dentre outros.

Assim, o crescimento da força de trabalho docente vem sendo marcado pela flexibilização dos contratos de trabalho. Na análise de Bosi (2007): 
São essas possibilidades de contratação precária, abertas por práticas constituídas à margem da lei ou mesmo por modificações na legislação trabalhista, que têm feito com que o número de docentes aumente. Nesse sentido, é certo também que, tornado numericamente predominante, o trabalho considerado precário e informal tende a converter-se em medida para todo tipo de trabalho restante. Este é o principal fundamento histórico do processo que atravessamos (p. 1510).

Todavia, a flexibilização não se restringe ao tipo de contrato que é oferecido, pois em nome deste princípio tem-se assistido a um aumento substantivo do trabalho docente, um processo ainda inconcluso e que é objetivado tanto na educação privada, quanto na pública. $O$ estratégico dessas alterações é que os novos protocolos destinados aos docentes envolvem mecanismos que têm por alvo a intensificação e extensão do trabalho, relacionando-o às demandas e/ou lógica de mercado.

Um caso exemplar do que se está afirmando ocorreu com os professores das universidades federais brasileiras. No âmbito do trabalho docente das instituições federais, uma mudança nas regras da remuneração por parte do MEC, no ano de 1998 (governo FHC), durante uma greve que se estendia por três meses, estabeleceu uma gratificação por produção chamada de Gratificação de Estímulo à Docência (GED). Inspirada nos manuais de reengenharia e da qualidade total, pela nova gratificação, parte substantiva da remuneração do professor passou a depender de sua "produtividade" individual. Foi criada, portanto, "como instrumento indutor de transformações das práticas docentes" (Leher \& Lopes, 2008: 83), estabelecendo que o valor da gratificação recebida pelos docentes dependeria de um sistema de pontuação que estabelecia parâmetros para a avaliação da prática docente e conformava uma determinada idéia do que deveria constituir a atividade de um professor universitário. Em síntese, a GED provocou uma estrondosa intensificação do trabalho docente, associando, ainda, um significativo aumento do número médio de alunos em relação a cada docente.

De lá para cá, o uso deste tipo de mecanismo só se refinou, pois na exata medida em que o repasse regular de recursos para as instituições federais encontra-se praticamente congelado, desde meados dos anos 1990, configura-se um contexto fértil para a indução de políticas que forçam a elevação da produção. A partir de 2007, por exemplo, com a aprovação do Programa de Reestruturação e Expansão das Universidades Federais 
(REUNI, Decreto Presidencial no 6.096 de 24 de Abril de 2007), até o custeio de atividades básicas dependerá de contratos de gestão com o Estado. Com este Programa - operacionalização, na prática, dos contratos de gestão, ensaiados desde o governo de $\mathrm{FHC}$-, recursos somente serão disponibilizados se a universidade alcançar metas de expansão como:

[...] aumentar o número de estudantes de graduação nas universidades federais; aumentar o número de alunos por professor em cada sala de aula da graduação; diversificar as modalidades dos cursos de graduação, através da flexibilização dos currículos, da educação a distância, da criação dos cursos de curta duração, dos ciclos (básico e profissional) e bacharelados interdisciplinares; incentivar a criação de um novo sistema de títulos; elevar a taxa de conclusão dos cursos de graduação para $90 \%$ e estimular a mobilidade estudantil entre as instituições de ensino (Lima, 2008: 68).

Em síntese, em 2007, as universidades federais assinaram um "termo de pactuação de metas" que só serão atingidas com a intensificação e heteronomia do trabalho docente e/ou com o aligeiramento dos cursos. A qualidade atualmente aferida para as universidades federais será rebaixada e insuficiente para uma formação ampla e crítica. Por fim, à grande parte das universidades federais restará a alternativa de aprofundar suas ações de profissionalização e amargar uma nova concepção de autonomia que, conforme Meek (2002), configura-se tão somente na liberdade de atender aos objetivos oficiais, caracterizando uma autonomia para livremente conformar-se.

\section{Nova cultura institucional: o docente produtivo, competitivo e empreendedor}

A implementação das reformas neoliberais dos anos 1990 não afetou somente aspectos objetivos das relações entre docentes, seus empregadores e protocolos de trabalho. Implicou um processo de redistribuição do poder social que acarretou modificações no próprio modo como cada grupo social se auto-representa, se pensa e configura seu destino social no trabalho e na própria sociedade.

É preciso considerar, portanto, os novos funcionamentos das organizações contemporâneas e as representações do trabalho que emergiram de todas essas mudanças, afetando, dentre outras, o ethos das instituições educacionais. Conforme análise de Silva Júnior e Sguissardi (2005): 
A um só tempo, a educação assume a centralidade nos discursos de gestores políticos e empresariais e de educadores, tendo a mídia em geral, com raras exceções, a lhes fazer entusiástico coro. Seduzidos por tal centralidade, os trabalhadores cada vez mais assumem individualmente a busca de condições para se tornarem capazes e empregáveis por meio da educação escolar. Suas qualidades subjetivas parecem-Ihes verdadeira mercadoria, algo objetivo, adquirido mediante pagamento e que os tornaria empregáveis numa sociedade cada vez mais sem emprego (p.12).

Especificamente em relação aos docentes, um dos principais dispositivos utilizados para conformá-los, ao mesmo tempo em que a quantidade de trabalho aumenta, está alicerçado na idéia de que os professores devem ser "mais produtivos", correspondendo a "produção" à quantidade de "produtos" declarados, que além das aulas, incluem orientações, publicações, projetos, patentes, apresentações e participações em eventos dentre outros (Bosi, 2007).

Esse processo tem seu paralelo no direcionamento empresarial da ciência, tecnologia, pesquisa e desenvolvimento, presente nos editais dos órgãos (públicos) de fomento à produção científica, onde dois tipos merecem citação e análise.

Primeiramente, tem-se os editais "universais" que se propõem a oferecer recursos para suprir os meios de produção acadêmicos (livros, laboratórios, computadores, equipamentos, material de consumo, bolsas etc.) que os cortes orçamentários deixaram de oferecer. Obviamente, que os recursos não são suficientes para todos, os pares devem competir por eles, ganhando os mais produtivos.

Mas, também há os editais que convertem seus recursos para pesquisas e estudos que aparelhem e potencializem a capacidade de reprodução do capital, numa clara adesão à razão instrumental. Neste caso, tem-se editais públicos e/ou associados a empresas. Eles são os mais vultosos, destinam-se às investigações com resultados imediatos que conduzam à mais eficaz aplicação com vistas ao fortalecimento do capital nacional industrial e agropecuário exportador, investimento que privilegia, assim, as "áreas duras" em detrimento das ciências humanas, dentre elas a educação (Silva Júnior \& Sguissardi, 2005: 10).

Nos dois casos, a lógica do financiamento transforma o docentepesquisador num empreendedor e o leva a adequar a sua criação intelectual 
aos editais, a um determinado valor mensurado de uma forma determinada, conforma o seu labor a padrões possíveis, restringindo os temas e metodologias a serem adotadas. Essas acomodações podem ser mais ou menos distantes das expectativas originais do pesquisador, mas certamente exigirá uma intensificação considerável do seu trabalho, particularmente na pós-graduação (Leher \& Lopes, 2008) e alta dose de espírito competitivo.

Assim, na cultura acadêmica mercantilizada, entre os novos atributos valorizados, destacam-se "o empreendedorismo, a gana de captar recursos custe-o-que-custar, inclusive em detrimento da própria capacidade crítica"! (Leher \& Lopes, 2008: 87) Ao fim e ao cabo, o docente que consegue agregar ao seu salário e à própria instituição maior montante de recursos é o mais produtivo, competitivo e valorizado.

O resultado dessa política tem se materializado num crescimento desmedido da produtividade acadêmica e contribuído para a hierarquização e privatização da universidade, pois à medida que os recursos disponíveis para a pesquisa são canalizados só para alguns, eles passam a ser usados privativamente dentro da própria instituição pública. Laboratórios, computadores, salas, auditórios e equipamentos servem apenas e exclusivamente aos grupos, núcleos e centros de pesquisa que captaram verbas públicas (dos editais) para essa construção.

Esse aspecto financeiro faz-se acompanhar de uma verdadeira ressocialização dos docentes, que toma por base um padrão produtivista e um tipo de "cultura do desempenho", sob a qual o trabalho docente é permanentemente pontuado, traduzido em números e intensificado através de diversos e complexos sistemas de avaliação ditos institucionais que, ano a ano, alargam as exigências de produção acadêmica. Os cursos de graduação têm sido classificados e hierarquizados, no Brasil, desde o "Provão" (19962003) e, mais recentemente, através do Sistema Nacional de Avaliação da Educação Superior - SINAES (Lei no 10.861, de 15 de Abril de 2004); os programas de pós-graduação recebem conceitos que vão de 1 a 7 e seus financiamentos dependem da nota obtida; os artigos científicos são valorizados de acordo com o periódico que o veicula, isto é, conforme o "Qualis/CAPES" (um indexador nacional oficial que classifica os periódicos em 9 níveis), já se encontra em andamento um "Qualis" para livros e para participação em eventos... Enfim, a produção docente é mensurada, tipificada 
e classificada por critérios quantitativos, cada vez mais refinados, abrangentes e exigentes!

O docente é "valorizado" por essas avaliações, onde pesam a inserção na pós-graduação, o número de orientações, artigos e livros publicados e o próprio fato de ter uma "bolsa de produtividade em pesquisa" que consegue por méritos próprios no CNPq (Conselho Nacional de Desenvolvimento Científico e Tecnológico). Institucionaliza-se uma hierarquização entre os docentes, legitima-se uma "elite acadêmica" definida como tal pelo desempenho conseguido nos editais de pesquisa, nas bolsas captadas para si e para estudantes, pelos escores que alcança na produtividade acadêmica. Essa dinâmica é tão forte e entranhada na cultura institucional que a própria ética na pesquisa é subtraída. Assim, além da baixa qualidade dos trabalhos, muitos deles se multiplicam pelo artifício do autoplágio e já se tem casos comprovados de fraude, em instituições brasileiras de reconhecimento internacional, em função da "pressão por resultados" e do prestígio que trazem ao pesquisador.

A expressão mais requintada dessa panóplia avaliativa incide sobre a Coordenação de Aperfeiçoamento de Pessoal de Nível Superior (CAPES) e a avaliação que faz da pós-graduação no Brasil. A CAPES, outrora, desempenhara um papel relevante na organização do sistema de pósgraduação brasileiro, mas acabou por incorporar, difundir e aprofundar a mesma lógica produtivista, pragmática e utilitarista anteriormente analisada. Em lugar de avaliar o programa, suas dificuldades, potencialidades e relevância para a instituição e para a região, o resultado da avaliação depende de uma planilha de indicadores cujo foco incide diretamente sobre cada professor credenciado na pós-graduação: inicialmente, exigindo um padrão produtivista, depois, restringindo o campo possível desse produtivismo, impondo que as publicações sejam limitadas a um conjunto de periódicos qualificados e que a produção do conhecimento gere produtos úteis.

A cultura da produtividade afeta toda a instituição universitária, de modo que mesmo os alunos da graduação e da pós-graduação recebem fortes pressões para que sejam produtivos e cumpram os prazos, muitas vezes a despeito da qualidade final de seus trabalhos. 
Envolvidos nesse ambiente de intensa produtividade, competitividade e empreendedorismo torna-se difícil a produção de um pertencimento coletivo que se dê pela percepção de que é preciso organização e mobilização para mudança do próprio sistema. Ao contrário, o padrão que é socializado deita raízes em práticas e valores individualistas, onde a competição é a regra. $\mathrm{A}$ escassez de recursos para pesquisa (e para o trabalho docente em geral) também é naturalizada e se transforma em realidade que avaliza a "competência" dos que conseguem acessar tais recursos (Mancebo; Silva Júnior \& Oliveira, 2008).

\section{Considerações finais em quatro aspectos}

1. Os eixos analíticos e críticos arrolados neste texto a respeito das políticas para a educação superior no Brasil não são de autoria de um único governo. Constituem-se em marcos de continuidade de medidas tomadas anteriormente, mas aprofundadas a partir dos anos 1990, a partir de um viés neoliberal: neoliberal-conservador (no governo Cardoso) e neoliberalpopulista, mais ao estilo do governo Lula da Silva, a ponto de levar a população de baixa renda a sentir-se contemplada por certa dose de "justiça social" (Mancebo; Silva Júnior \& Oliveira, 2008).

2. As políticas implementadas e seus efeitos sobre o trabalho docente desenvolvem-se num marco mais amplo, num contexto determinante, de modo que algumas categorias destacadas e analisadas ao longo deste texto - empresariamento, privatização, mercantilização, produtividade, heteronomia institucional e profissional, competitividade, conformismo encontram-se muito próximas e são complementares às principais categorias de reformas advogadas nos acordos de Bolonha, nas fórmulas do Banco Mundial e nas proposições dos Tratados de Livre Comércio. São conceitos que tornam a gestão das universidades cada vez mais parecidas com a de uma empresa, esvaecendo o seu caráter de instituição da sociedade voltada para a formação e para a produção do conhecimento inovador e engajado na solução de problemas nacionais.

Não se pode estranhar, portanto, que em diversos países além do Brasil encontre-se ações muito próximas às aqui discutidas, tais como:

a) a gradativa desresponsabilização do Estado com o financiamento $\mathrm{e}$ a manutenção da educação superior, embora mantendo sobre ela estrito e 
crescente controle, via sistemas de avaliação, regulação, controle e credenciamento; b) o estímulo e as facilidades para a criação e expansão de IES privadas sem e com fins lucrativos; c) a indução a que as IES públicas sejam organizadas e geridas à semelhança de empresas econômicas; d) a valorização da qualidade acadêmica em moldes administrativo- gerenciais e empresariais: produto, custo/benefício; e) o incentivo à competição intra e interinstitucional; f ) a manutenção [das instituições públicas] sem autonomia de gestão financeira [...]; g) o implemento à diversificação das fontes de financiamento [nas instituições públicas], mediante, entre outras medidas, [...] a cobrança de mensalidades, contratos de pesquisa com empresas, venda de serviços e consultorias e doações da iniciativa privada; h) o implemento à diferenciação institucional [quanto a...] carreira docente [...], salários individualizados por volume de aulas e de produção científica, dentre outras ações (Sguissardi, 2006, p.1038-1039).

3. A oposição e resistência coletiva a todo este quadro têm sido difícil. Primeiramente, porque a mercadorização das relações na universidade pressupõe o arrefecimento do potencial crítico de que a universidade dispõe e também porque toma parte desta cultura desqualificar aqueles que se opõem a esse sistema, apontados como militantes/improdutivos. Segue-se, ainda, que importantes segmentos universitários aderiram, pragmaticamente, à tese de que em não se podendo reverter o processo de mercantilização em curso, deve-se atenuá-lo para si, o que significa, trocando em miúdos, tornarse também um empreendedor. Assim considerando, as condições históricas do trabalho docente nas instituições brasileiras, ainda carecem de problematização, reflexão, denúncias sistemáticas e de iniciativas cotidianas de combate ao produtivismo, à mercantilização e à cultura individualista que assolam as instituições de educação superior. Reitera-se, portanto, a imperiosa necessidade de se retomar a via de uma conceitualização política, crítica e comprometida que, "sin abandonar la lectura de los procesos que se desarrollan desde abajo, aborde el desafío de pensar en términos macrosociales y estructurales las posibilidades de una política instituyente" (Svampa, 2007: 2). O diagnóstico aqui exposto remete, portanto, a uma responsabilidade maior: a da ampliação de categorias teóricas, sínteses explicativas mais fortes, críticas, que potencializem a ação coletiva de contestação e a mudança radical. 
4. Por fim, deve-se considerar que ações isoladas, mesmo que exemplares, são insuficientes e que uma reforma radical da universidade requer avanços coletivos nas lutas anticapitalistas, com as quais deve-se dialogar e interagir para que a universidade possa levar adiante sua responsabilidade crítica diante da sociedade. Nesse sentido, a imagem criada por Svampa (2007) é bastante sugestiva: conjugar em um só paradigma, as figuras do docente/pesquisador e do militante como "un anfíbio, a saber, una figura capaz de habitar y recorrer varios mundos, y de desarrollar, por ende, una mayor comprensión y reflexividad sobre las diferentes realidades sociales y sobre sí mismo" (p.11).

\section{Notas}

1 Versão preliminar desse texto foi apresentada, oralmente, no VII Seminário da Rede Latino-americana de Estudos Sobre Trabalho Docente, na mesa redonda intitulada "Trabalho docente na educação superior: tensões e novos sentidos", em 5 de julho de 2008, na Universidade de Buenos Aires.

2 Foram várias as fontes consultadas para tal empenho. Pode-se citar como principais: os textos advindos de autores do GT Políticas da Educação Superior da Associação Nacional de Pós-graduação e Pesquisa em Educação (GT 11 da ANPEd), alguns dos quais publicados no site www.anped11.uerj.br; os produzidos no âmbito do Sindicado Nacional dos Docentes das Instituições de Ensino Superior (ANDES-SN), especialmente aqueles aprovados em seus Congressos e os publicados na Revista Universidade \& Sociedade e as publicações da Revista Educação \& Sociedade que já dedicou alguns de seus números a dossiês temáticos sobre o tema.

3 O caráter da crise atual (de 2008) e de seus efeitos para os diversos países deve ser analisado considerando-se exatamente o processo de transferência de capitais do setor produtivo para o especulativo que a desregulamentação promoveu em escala nacional e internacional. Como observou Sader (2008) "Livre de travas, o capital migrou maciçamente para o setor financeiro e, em particular, para o setor especulativo, onde obtêm muito mais lucros, com muito maior liquidez e com menos ou nenhuma tributação para circular" (p. 1-2).

4 Estudo realizado pela UNESCO e apresentado na Conferência Regional de Educação Superior, ocorrida em junho de 2008, em Cartagena, Colômbia, considerou o Brasil como o país da América Latina com a menor porcentagem de universitários em instituições públicas. 


\section{Referências}

ALVES, Giovanni (2000). O Novo (e Precário) Mundo do Trabalho: reestruturação produtiva e crise do sindicalismo. São Paulo: Boitempo.

ANTUNES, Ricardo (1999). Os Sentidos do Trabalho: ensaio sobre a afirmação e a negação do trabalho. São Paulo: Boitempo.

BOSI, Antônio de Pádua (2007). A precarização do trabalho docente nas instituições de ensino superior do Brasil nesses últimos 25 anos. Educação \& Sociedade, Campinas, vol. 28, no 101, pp. 1503-1523 [Em linha] [Acedido em 10 de Junho de 2008, disponível em http://www.cedes.unicamp.br].

Decreto no 6.096 de 24 de Abril de 2007 [Em linha] [Acedido em 16 de Junho de 2008, disponível em http://www.mec.gov.br].

DOURADO, Luiz Fernandes (2008). Políticas de expansão da educação superior no Brasil e a modalidade EaD. In D. Mancebo; J. R. Silva Júnior \& J. F. Oliveira (Orgs.), Reformas e Políticas: Educação Superior e Pós-graduação no Brasil. São Paulo: Alínea, pp. 97-116.

GRAMANI, Maria Cristina Nogueira (2008). A influência da qualidade na atratividade de instituições de ensino superior com capital aberto. Ensaio: Avaliação e Políticas Públicas em Educação, Rio de Janeiro, vol. 16, no 60, pp. 437-454.

LEHER, Roberto \& LOPES, Alessandra de Barros Piedras (2008). Trabalho docente, carreira, autonomia universitária e mercantilização da educação. In D. Mancebo; J. R. Silva Júnior \& J. F. Oliveira (Orgs.), Reformas e Políticas: Educação Superior e Pós-graduação no Brasil. São Paulo: Alínea, pp. 73-96.

Lei no 9.394 de 20 de Dezembro de 1996. Diário Oficial da União, ano CXXXIV, no 1.248 de 23 Dezembro de 1996.

Lei $\mathrm{n}^{0} 10.861$ de 15 de Abril de 2004 [Em linha] [Acedido em 15 de Maio de 2008, disponível em http://www.presidencia.gov.br].

Lei no 10.973 de 2 de Dezembro de 2004 [Em linha] [Acedido em 1 de Junho de 2008, disponível em http://www.presidencia.gov.br].

Lei $n^{\circ} 11.096$ de 13 de Janeiro de 2005 [Em linha] [Acedido em 1 de Junho de 2008, disponível em http://www.presidencia.gov.br].

LIMA, Kátia (2008). Reformas e políticas de educação superior no Brasil. In: In D. Mancebo; J. R. Silva Júnior \& J. F. Oliveira (Orgs.), Reformas e Políticas: Educação Superior e Pós-graduação no Brasil. São Paulo: Alínea, pp. 54-72.

MANCEBO, Deise; SILVA JÚNIOR, João dos Reis \& OLIVEIRA, João Ferreira de (Orgs.) (2008). Reformas e Políticas: Educação Superior e Pós-graduação no Brasil. São Paulo: Alínea.

MARX, Karl (1981). O Capital: livro 3. Rio de Janeiro: Civilização Brasileira. v. 4, p. 241265.

MEC.INEP. Ministério da Educação. Instituto Nacional de Estudos e Pesquisas Educacionais (2002). Sinopses da Educação Superior. Brasília, DF: Ministério da Educação [Em linha] [Acedido em 10 de Junho de 2008, disponível em http://www.inep.gov.br]. 
MEC.INEP. Ministério da Educação. Instituto Nacional de Estudos e Pesquisas Educacionais (2006-a). Sinopses da Educação Superior. Brasília, DF: Ministério da Educação [Em linha] [Acedido em 10 de Junho de 2008, disponível em http://www.inep.gov.br].

MEC.INEP. Ministério da Educação. Instituto Nacional de Estudos e Pesquisas Educacionais (2006-b). Cadastro Nacional de Docentes da Educação Superior. Brasília, DF: Ministério da Educação [Em linha] [Acedido em 10 de Junho de 2008, disponível em http://www.inep.gov.br]

MEC.INEP. Ministério da Educação. Instituto Nacional de Estudos e Pesquisas Educacionais (2008). Evolução do Ensino Superior-Graduação 1988-1999. Brasília, DF: Ministério da Educação [Em linha] [Acedido em 10 de Junho de 2008, disponível em http://www.inep.gov.br].

MEEK, Van Lynn (2002). Use of the "Market" in the Transformation of Australian Higher Education. In R. Rodriguez Gómez (Org.), Reformas en los Sistemas Nacionales de Educación Superior. La Coruña, Es: Netbiblo, pp. 149-78.

SADER, Emir (2008). Os ciclos e as crises. Adital, 18 de Setembro de 2008 [Em linha] [Acedido em 5 de Novembro de 2008, disponível em http://www.adital.com.br/site/noticia.asp].

SGUISSARDI, Valdemar (2006). Reforma universitária no Brasil - 1995-2006: Precária trajetória e incerto futuro. Educação \& Sociedade, Campinas, vol. 27, no 96, pp. 1021-1056.

SILVA JÚNIOR, João dos Reis \& SGUISSARDI, Valdemar (2005). A nova lei de educação superior: fortalecimento do setor público e regulação do privado/mercantil ou continuidade da privatização e mercantilização do público? Revista Brasileira de Educação, no 29, pp. 5-28.

SVAMPA, Maristella (2007). Reflexiones sobre la Sociología crítica en América Latina y el compromiso intelectual. Comunicação apresentada no XXVI Congreso de la Asociación Latinoamericana de Sociología (ALAS), Guadalajara, 13 a 18 de Agosto. 
TEACHING IN BRAZILIAN HIGHER EDUCATION: MERCANTILIZATION OF RELATIONS AND ACADEMIC HETERONOMY

\begin{abstract}
The article analyzes the flex contractual relations of teaching in institutions of higher education; the transformations in teaching, research and extension and the changes in the culture of the institutions of higher education in Brazil. For such, the main legal documents had been consulted and diverse official pointers, taking as basic axle of analysis, the mercantilization of higher education, in the landmark of the changes happened in the world work, from years 1970 in world-wide scale.
\end{abstract}

Keywords

Teaching; Higher Education; Privatization of Higher Education 
TRAVAIL DES ENSEIGNANTS DES INSTITUTIONS D'ĖDUCATION SUPÉRIEURE AU BRÉSIL

\section{Résumé}

Cet article met en évidence l'infléchissement des rapports contractuels du travail des enseignants des Institutions d'Èducation Supérieure, ainsi que les changements opérés dans leur production (l'enseignement, la recherche et l' "extension") et les modifications subies par la culture des Institutions d'Education Supérieure au Brésil. Dans ce but, plusieurs dispositions légales et indicateurs officiels ont été vérifiés, à partir d'une analyse de la mercantilisation de l'Éducation Supérieure, dans le cadre des changements advenus dans le monde du travail, à partir des années 1970, dans une échelle mondiale.

Mots-clé

Travail de l'éducateur; Education Supérieure; Privatisation de l'Education Supérieure

Recebido em Fevereiro/2009 Aceite para publicação em Agosto/2010 